\title{
Persistence of Imidacloprid, Indoxacarb and Lambda-Cyhalothrin on Tomato (Solanum lycopersicum L.) Under Protected Cultivation
}

\author{
Prem Chand Sharma*, Priyanka, Chandresh and Sugandha Sharma \\ Department of Entomology, CSK Himachal Pradesh Krishi Vishvavidyalaya, \\ Palampur-176 062, India \\ *Corresponding author
}

\section{A B S T R A C T}

\begin{tabular}{|c|}
\hline Keywords \\
\hline $\begin{array}{l}\text { Persistence, } \\
\text { Insecticides, } \\
\text { Protected } \\
\text { cultivation, } \\
\text { Residues, Tomato }\end{array}$ \\
\hline Article Info \\
\hline $\begin{array}{l}\text { Accepted: } \\
20 \text { June } 2018 \\
\text { Available Online: } \\
10 \text { July } 2018\end{array}$ \\
\hline
\end{tabular}

Keywords

\section{Introduction}

Protected cultivation is the most intensive method of crop production which provides protection to plants from adverse environmental conditions. Maharashtra, Karnataka, Himachal Pradesh, North-eastern states, Uttarakhand, Tamil Nadu and Punjab are the leading Indian states adopting this technology with approximate area of 30,000 hectares (Anonymous, 2012). The major crops being grown under protected conditions are tomato, capsicum, cucumber, melons,

\begin{abstract}
The present studies were carried out under protected cultivation at CSK Himachal Pradesh Krishi Vishvavidyalaya, Palampur. Single spray of three insecticides viz., imidacloprid $(0.018 \%)$, indoxacarb $(0.015 \%)$ and lambda-cyhalothrin $(0.004 \%)$ was given on tomato crop. The residues of imidacloprid and indoxacarb were worked out on tomato fruits during winter season 2015 whereas lambda-cyhalothrin residues were worked out during summer season 2016. Tomato fruit samples were collected at $0,1,3,5,7$ and 10 days after application of insecticides. The residues were analyzed using High Performance Liquid Chromatography. The initial deposits of imidacloprid, indoxacarb and lambda-cyhalothrin on tomato fruits were $0.643,0.401$ and $0.550 \mathrm{mg} / \mathrm{kg}$, respectively. The residues of all the insecticides were below detectable limits on $10^{\text {th }}$ day of application. The half-life values of imidacloprid, indoxacarb and lambda-cyhalothrin were 2.91, 5.26 and 3.06 days, respectively. The corresponding safety intervals were worked out to be $0.36,0.46$ and 1.03 days for imidacloprid, indoxacarb and lambda-cyhalothrin.
\end{abstract}

strawberry, rose, gerbera, carnation and chrysanthemum. Among vegetables, tomato (Solanum lycopersicum L.) is the preferred crop in greenhouses worldwide (Singh, 2005). The year-round demand for high quality tomatoes can only be achieved through protected cultivation. The present area under protected cultivation in Himachal Pradesh is about 350 hectares (Anonymous, 2014) and is famous for the production of off-season vegetable like tomato fetch remunerative price in the North Indian plains. 
Due to congenial conditions under protected environment, heavy incidence of insect-pests has been observed. One of the major factors which limit the successful cultivation of tomato crop is the variety of insect pests. These are cut worms, fruit borer, white fly, mite, serpentine leaf miner and fruit flies, which attack the crop at one or other stages of the crop growth, thus reduce the yield to a considerable extent (Sharma et al., 2004; Faqiri and Kumar, 2016). Among these insect pests, tomato fruit borer, Helicoverpa armigera (Hubner) (Lepidoptera: Noctuidae) is one of the most serious pest. It has been reported to inflict 20-60 per cent loss in fruit yield (Faqiri and Kumar, 2014; Kakar et al., 1990; Pareek and Bhargava, 2003; Mustafiz et al., 2015).

Tobacco caterpillar, Spodoptera litura (Fabricius) (Lepidoptera: Noctuidae) is a polyphagous pest that has now gained a status of pest in polyhouses. There are reports of its heavy infestations in isolated areas within the greenhouses. Vashisth (2009) has reported 51.4, 25.0 and 75.0 per cent infestation by $S$. litura on sweet pepper, tomato and cucumber, respectively under polyhouse conditions.

Several insecticides have been recommended for the management of insect-pests of tomato including tobacco caterpillar. No doubt the insecticides are effective for the control of pests, but their indiscriminate and excessive use has resulted in pollution of environment and adversely affected the health of the consumers. To be effective, these chemicals need to exhibit some persistence. The consequence of this is that residues of the original material or its metabolites may remain in/on food giving a potential threat for consumers. The use of insecticides as per the crop label claim approved by Central Insecticide Board and Registration Committee (CIB\&RC) is another constraint in use of insecticides on a particular crop. Since the tomato is harvested at short and regular intervals and consumed raw as well as in cooked form, the large scale use of these insecticides calls for the evaluation of persistence of some insecticides and finding their residues to determine their waiting periods on tomato under protected conditions.

\section{Materials and Methods}

The present studies were carried out at CSK Himachal Pradesh Krishi Vishvavidyalaya, Palampur during 2015-16. Tomato (var. Palam Tomato Hybrid 1) crop was raised in polyhouse (naturally ventilated), Department of Entomology. The crop was transplanted as per recommendations in Package of Practices for Vegetable Crops of CSK Himachal Pradesh Krishi Vishvavidyalaya, Palampur in insecticide free environment. Thirty days old seedlings were transplanted on $15^{\text {th }}$ March during summers and on $3^{\text {rd }}$ September during winter with the spacing of $45 \times 30 \mathrm{~cm}$. Each treatment was replicated thrice comprising 6 plants in each plot (i.e., control, imidacloprid, indoxacarb and lambda-cyhalothrin @ 0.018, 0.015 and $0.004 \%$, respectively) and arranged in a randomized block design. Application of insecticides was given in May during summers and in November during winter season. In control plots, only water was sprayed.

\section{Sampling procedure}

Tomato fruit samples (250g each) were collected from each replication in polythene bags at an interval of $0,1,3,5,7,10$ and 15 days after first spray. The samples were packed in polythene bags, labeled well and brought to laboratory for pesticide residue analysis.

\section{Extraction and clean up}

Imidacloprid: Imidacloprid residues on tomato were analyzed as per the method of 
Vladi et al., (2014) with some modifications. A representative $50 \mathrm{~g}$ sample was extracted with methanol $(200 \mathrm{ml})$ in a blender for 3 minutes with a high speed and filtered. After evaporation of methanol extract in a rotary vacuum evaporator, the remaining aqueous phase was diluted with saturated solution of sodium chloride and partitioned with n-hexane (100ml). The organic phase was discarded. The aqueous phase was partitioned again with 100,50 and $50 \mathrm{ml}$ of dichloromethane in separatory funnel. The lower dichloromethane layers were passed through anhydrous sodium sulphate and concentrated to dryness in a rotary vacuum evaporator at $40^{\circ} \mathrm{C}$. After evaporation of DCM, the residues were dissolved in $2 \mathrm{ml}$ ethyl acetate. For cleanup of the extracted samples of imidacloprid, the chromatography column $(50 \times 1.5 \mathrm{~cm})$ was prepared by adding silica gel over $2 \mathrm{~cm}$ layer of anhydrous sodium sulphate (Dharmurajan and Dikshit, 2010). The imidacloprid was eluted from the column with $25 \mathrm{ml}$ of HPLCgrade acetonitrile which was evaporated just to dryness and residues re-dissolved in an appropriate volume $(10 \mathrm{ml})$ of HPLC-grade acetonitrile. Then the residues were ready for analysis by HPLC.

Indoxacarb: Indoxacarb residues on tomato were analyzed as per the procedure suggested (Sharma and Mahapatra, 2005). Tomato samples (50g each) were macerated with $50 \mathrm{ml}$ of acetonitrile in a mixer blender for 2 minutes at high speed. The samples were then filtered through Buchner funnel under vacuum using Whatman No. 1 filter paper. The filtrates were then concentrated to about $5 \mathrm{ml}$ under reduced pressure using rotary vacuum evaporator and quantitatively transferred to the top of the column. The column was eluted with $10 \mathrm{~g}$ activated silica gel $\left(110^{\circ} \mathrm{C}\right.$ for 1 hour $)$. The eluate was evaporated just to dryness and residues re-dissolved in an appropriate volume (10ml) of HPLC-grade acetonitrile for analysis by HPLC.
Lambda-cyhalothrin: Lambda-cyhalothrin residues on tomato were analyzed as per the method of Ahmed et al., (2015) with slight modifications. Tomato sample $(50 \mathrm{~g})$ was macerated with $100 \mathrm{ml}$ of acetone in a warring blender for 2 minutes at high speed. The blended samples was transferred to $250 \mathrm{ml}$ conical flask by using acetone $(2 \times 20 \mathrm{ml})$ and shaken for $30 \mathrm{~min}$ in a mechanical shaker. The sample was then filtered through Buchner funnel under suction using Whatman No. 1 filter paper. The extract was then concentrated under reduced pressure using rotary vacuum evaporator. The concentrated extract was transferred to separatory funnel and $100 \mathrm{ml}$ saturated $\mathrm{NaCl}$ solution was added for salting out effect. Then the aliquot was partitioned with $75 \mathrm{ml}$ dichloromethane (DCM). The DCM layer was collected after passing through activated anhydrous sodium sulphate. The process was repeated twice with dichloromethane and the DCM layers were pooled \& concentrated to dryness using rotary vacuum evaporator. The residues were dissolved in $5 \mathrm{ml}$ hexane-acetone (9:1) mixture and passed through pre-washed column $(45 \times 1.5 \mathrm{~cm})$ packed with $10 \mathrm{~g}$ of activated alumina over $2 \mathrm{~cm}$ layer of anhydrous sodium sulphate. After loading the residues, the column was eluted with $150 \mathrm{ml}$ of hexaneacetone (9:1) mixture. The eluate was evaporated to dryness using rotary vacuum evaporator. The final volume was reconstituted with $10 \mathrm{ml}$ acetonitrile for analysis of lambda-cyhalothrin residues by HPLC.

\section{Instrumental analysis}

The estimation of imidacloprid, indoxcarb and lambda-cyhalothrin residues was done by using HPLC (Shimadzu) equipped with a UVVIS detector and auto-sampler. The injection volume was $20 \mu 1$. The wavelength for imdiacloprid was $270 \mathrm{~nm}$ while it was $310 \mathrm{~nm}$ for indoxacarb and $230 \mathrm{~nm}$ for lambda- 
cyhalothrin with retention times of 5, 3.5 and 15.8 minutes, respectively.

\section{Recovery experiments}

Recovery experiments were carried out to know the efficiency of the analytical method used in the studies. These were conducted by fortifying tomato fruit samples with the insecticides at three levels i.e. $0.2,0.4,0.8 \mu \mathrm{g} / \mathrm{g}$ for each insecticides (indoxacarb, imidacloprid and lambda-cyhalothrin). The technical grade insecticides were manufactured by Dr. Ehrenstorfer $\mathrm{GmbH}$ Germany.

\section{Half life and Safety intervals}

The half-life or $\mathrm{RL}_{50}$ values of these insecticides were calculated on the basis of formula given by Hoskins (1961).

$\mathrm{t}_{1 / 2}=\log 2 / \mathrm{k}_{1}=0.301 / \mathrm{k}_{1}$

where

$\mathrm{t}_{1 / 2}=$ half-life value of residues

$\mathrm{k}_{1}=$ slope of regression coefficient $(\mathrm{b})$

of the $\log$ residues in $\mathrm{mg} / \mathrm{kg}$ (y) on the number of elapsed days ( $\mathrm{x}$ ).

The formula of Hoskins (1961) was also used for calculating safety intervals in days:

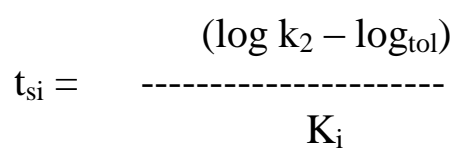

where

$\mathrm{t}_{\mathrm{si}}=$ the minimum number of days to be elapsed before the insecticides reached tolerance limit

$\log \mathrm{k}_{2}=\log$ of initial deposit

$\log _{\text {tol }}=\log$ of tolerance limit and

$\mathrm{ki}=$ Regression coefficient

\section{Weather data}

During the experimental period, the average minimum and maximum temperature during winter 2015 ranged from $10.0-14.0^{\circ} \mathrm{C}$ and $27.4-32.1{ }^{\circ} \mathrm{C}$, respectively with a relative humidity of $56.4-75.5 \%$. During summer 2016, the average minimum and maximum temperature fluctuated between $14.5-22.9^{\circ} \mathrm{C}$ and $28.9-41.1^{\circ} \mathrm{C}$, respectively. The average relative humidity ranged from 34.0-78.3 per cent.

\section{Results and Discussion}

\section{Residues of insecticides on tomato fruits}

The overall results of analysis of tomato fruits for insecticidal residues are presented in table 1.

\section{Chromatograms of insecticides}

Standard solutions of the three insecticides were prepared with their respective solvents. The peak area of standard insecticides at different concentrations is shown in table 1 and the standard curves are given in Figure 1, 2 and 3. The calibration curves of imidacloprid, indoxacarb and lambdacyhalothrin in HPLC showed that there existed a linearity in progression of peak area vis-àvis concentration of insecticides injected. The chromatograms of standard insecticides by HPLC are presented in Figure 4.

\section{Recovery of insecticides from tomato fruits}

The average per cent recovery of imidacloprid was 83.19 per cent. The results are in agreement with those obtained by Reddy et al., (2007b) who reported that the recovery for imidacloprid fortified tomato fruits varied from 79.2-89.4 per cent. The average recovery of indoxacarb was found to be 87.33 per cent which is similar to the results of Saimandir 
and Gopal (2009) from brinjal fruits. The average recovery of lambda-cyhalothrin was found to be 85.58 per cent. The results are in agreement with those obtained by Jayakrishnan et al., (2005) who reported the recovery of lambda-cyhalothrin from tomato fruits in the range of $49-93$ per cent. The minimum detectable limit was determined as $0.03 \mathrm{mg} / \mathrm{kg}$ each for imidacloprid and lambdacyhalothrin whereas it was $0.04 \mathrm{mg} / \mathrm{kg}$ for indoxacarb by using HPLC. Sharma and Mahapatra (2005) reported the limit of detection for indoxacarb as $0.001 \mathrm{mg} / \mathrm{kg}$. Reddy et al., (2007a) determined limit of detection for imidacloprid as $0.05 \mathrm{mg} / \mathrm{kg}$ in sweet pepper and tomato. For lambdacyhalothrin, a detection limit was found to be $0.01 \mathrm{mg} / \mathrm{kg}$ by Reddy et al., (2007a). Singh et al., (2011b) reported LOQ of $0.01 \mathrm{mg} / \mathrm{kg}$ of imidacloprid in okra.

\section{Insecticide residues}

The data on insecticide residues at different intervals are presented in table 2 and also depicted in Figure 5.

Imidacloprid: The initial deposits of imidacloprid $(0.018 \%)$ in tomato fruits were found to be $0.643 \mathrm{mg} / \mathrm{kg}$. The initial deposits dissipated to $0.393,0.188,0.100$ and $0.054 \mathrm{mg} / \mathrm{kg}$, thus resulting in reduction of $38.90,70.76,84.45,91.60$ per cent after 1, 3, 5 and 7 days of application, respectively. The residues were below detectable limits $(0.03 \mathrm{mg} / \mathrm{kg})$ on $10^{\text {th }}$ day.

Indoxacarb: Indoxacarb $(0.015 \%)$ application resulted in an average initial deposit of $0.401 \mathrm{mg} / \mathrm{kg}$ in tomato fruits. The residues declined to $0.320,0.203,0.117$ and $0.060 \mathrm{mg} / \mathrm{kg}$ on $1,3,5$ and 7 day of application, respectively, thus dissipating by 20.20, 49.38, 70.82 and 85.04 per cent. The residues were not detected on $10^{\text {th }}$ day.
Lambda-cyhalothrin: The initial deposits of lambda-cyhalothrin $\quad(0.004 \%) \quad$ were $0.550 \mathrm{mg} / \mathrm{kg}$ in tomato fruits. The residues reduced to $0.395,0.222,0.145$ and $0.048 \mathrm{mg} / \mathrm{kg}$ on $1,3,5$ and 7 days of spray, respectively and the per cent dissipation was 28.19, 59.64, 73.64 and 91.28 per cent, respectively. The residues were below detectable limits $(0.03 \mathrm{mg} / \mathrm{kg})$ on $10^{\text {th }}$ day of spray.

The present findings on initial deposits of imidacloprid residues on tomato are in agreement with those of Saryazdi et al., (2012) and Farouk et al., (2014). The initial deposits of $0.401 \mathrm{mg} / \mathrm{kg}$ in case of indoxacarb are more or less in accordance with the findings of Gupta et al., (2009) who found that mean initial deposits of indoxacarb varied from 0.259 to $0.382 \mathrm{mg} / \mathrm{kg}$ on okra fruits. The dissipation pattern of indoxacarb residues is in accordance with Sharma and Mohapatra (2005) who also reported that residues were below detectable limit on $10^{\text {th }}$ day after application in tomato fruits. The mean initial deposits of lambda-cyhalothrin (30g a.i./ha) on tomato fruits ranged from 0.385$0.526 \mathrm{mg} / \mathrm{kg}$ which declined with time and reached to non detectable level after 7-10 days of treatment (Jayakrishnan et al., 2005). The dissipation pattern of lambda-cyhalothrin residues was also in accordance with the findings of Reddy et al., (2007a).

\section{Half-life values}

The average half-life value of imidacloprid residues on tomato was found to be 2.91 days. These results are similar to those reported by Singh et al., (2011b) who found a half-life of 0.84 and 0.99 days of imidacloprid on okra at single and double doses, respectively. A halflife period of 1.29 and 0.86 days at single $(42 \mathrm{~g}$ a.i./ha) and double (84g a.i./ha) applications rates of imidacloprid in tomato fruits (Saryazdi et al., 2012). However, higher value 
of half-life (3.40 and 2.70 days at $30 \mathrm{~g}$ a.i./ha and $60 \mathrm{~g}$ a.i./ha respectively) of imidacloprid residues on cucumber fruits was observed (Nasr et al., 2014). This might be due to the variations in concentration, substrate, frequency and timings of application.

The half-life value of indoxacarb residues was 5.26 days. Sharma and Mohapatra (2005) reported the half-life value of 1.4-1.5 days for indoxacarb on tomato. A half-life of 0.58-1.02 days was found for indoxacarb on okra fruits (Gupta et al., 2009). The half-life value of $\lambda$ - cyhalothrin was found 3.06 days which differs from the results reported by Chauhan et al., (2011). They worked out half-life periods of 2.07 and 1.88 days at single (15g a.i./ha) and double (30g a.i./ha) application rates, respectively for lambda-cyhalothrin on tomato crop. This might be due to the difference in rate of application of lambda-cyhalothrin. Gupta et al., (2015) reported a half-life value of 2.65 days for lambda-cyhalothrin in brinjal fruits. However, a half-life value of 3.6-4.5 days on tomato was observed by Jayakrishnan et al.(2005).

Table.1 Peak area of insecticide standards at different concentrations

\begin{tabular}{|c|c|}
\hline Concentration $(\mathrm{mg} / \mathrm{kg})$ & Area \\
\hline \multicolumn{2}{|l|}{ Imidacloprid } \\
\hline 0.125 & 18038 \\
\hline 0.250 & 36563 \\
\hline 0.500 & 68667 \\
\hline 1.000 & 155691 \\
\hline 2.000 & 383170 \\
\hline \multicolumn{2}{|l|}{ Indoxacarb } \\
\hline 0.05 & 3240 \\
\hline 0.10 & 6798 \\
\hline 0.20 & 13961 \\
\hline 0.40 & 28938 \\
\hline 0.80 & 56540 \\
\hline \multicolumn{2}{|l|}{ Lambda-cyhalothrin } \\
\hline 0.125 & 5137 \\
\hline 0.250 & 11148 \\
\hline 0.500 & 26668 \\
\hline 1.000 & 5762 \\
\hline 2.000 & 1078563 \\
\hline
\end{tabular}


Table.2 Insecticide residues $(\mathrm{mg} / \mathrm{kg})$ in tomato fruits under protected cultivation

\begin{tabular}{|c|c|c|c|c|c|c|c|}
\hline \multirow[t]{2}{*}{ Insecticide } & \multirow{2}{*}{$\begin{array}{c}\text { Concentration } \\
(\%)\end{array}$} & \multicolumn{5}{|c|}{ Residues $(\mathrm{mg} / \mathrm{kg})$ at indicated days after spray } & \multirow{2}{*}{$\begin{array}{c}\text { Regression } \\
\text { equation }\end{array}$} \\
\hline & & 0 & 1 & 3 & 5 & 7 & \\
\hline Imidacloprid** & 0.018 & $0.643 \pm 0.036^{*}$ & $\begin{array}{c}0.393 \pm 0.007 \\
(38.90)\end{array}$ & $\begin{array}{c}0.188 \pm 0.015 \\
(70.76)\end{array}$ & $\begin{array}{c}0.100 \pm 0.012 \\
(84.45)\end{array}$ & $\begin{array}{c}0.054 \pm 0.012 \\
(91.60)\end{array}$ & $3.173-0.305 X$ \\
\hline Indoxacarb & 0.015 & $0.401 \pm 0.014$ & $\begin{array}{c}0.320 \pm 0.009 \\
(20.20)\end{array}$ & $\begin{array}{c}0.203 \pm 0.009 \\
(49.38)\end{array}$ & $\begin{array}{c}0.117 \pm 0.011 \\
(70.82)\end{array}$ & $\begin{array}{c}0.060 \pm 0.011 \\
(85.04)\end{array}$ & $2.878-0.208 X$ \\
\hline $\begin{array}{l}\text { Lambda- } \\
\text { cyhalothrin**** }\end{array}$ & 0.004 & $0.550 \pm 0.034$ & $\begin{array}{c}0.395 \pm 0.011 \\
(28.19)\end{array}$ & $\begin{array}{c}0.222 \pm 0.022 \\
(59.64)\end{array}$ & $\begin{array}{c}0.145 \pm 0.024 \\
(73.64)\end{array}$ & $\begin{array}{c}0.048 \pm 0.009 \\
(91.28)\end{array}$ & $3.067-0.255 \mathrm{X}$ \\
\hline
\end{tabular}

* Average of 3 replications; Figures following \pm signs are the standard deviations of the mean values; Figures in parentheses denote per cent dissipation;

**Residues studied in winter season, 2015; ***Residues studied in summer season, 2016;

MRL values: Imidacloprid $0.5 \mathrm{mg} / \mathrm{kg}$; Indoxacarb $0.5 \mathrm{mg} / \mathrm{kg}$; Lambda-cyahlothrin $0.3 \mathrm{mg} / \mathrm{kg}$ 


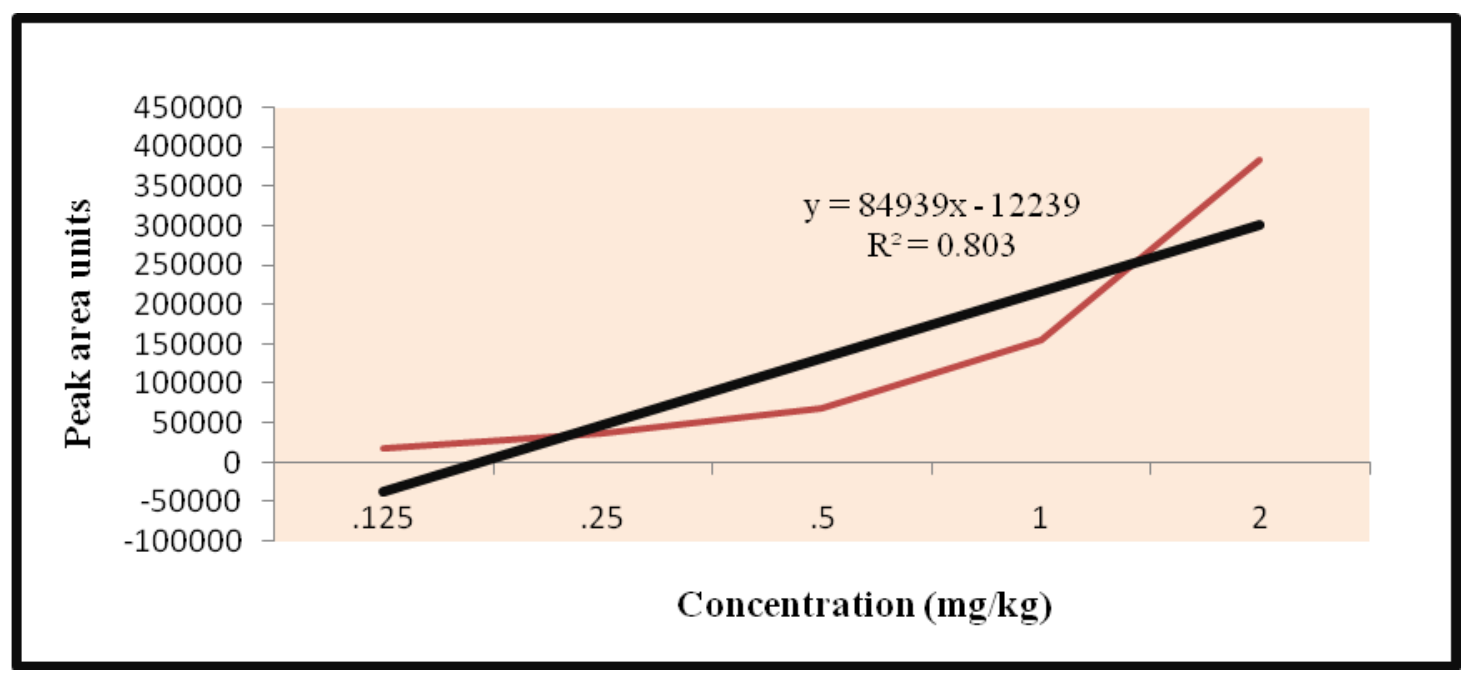

Fig.1 Calibration curve for imidacloprid

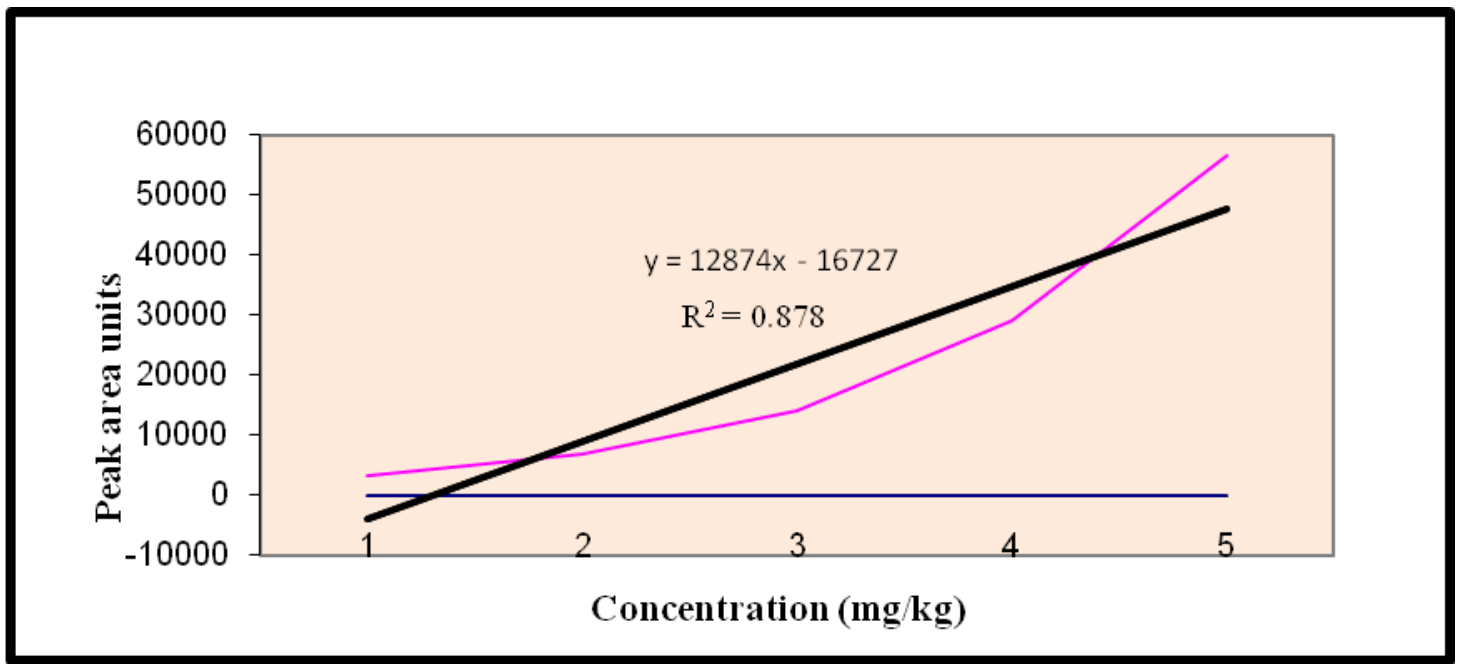

Fig.2 Calibration curve for indoxacarb

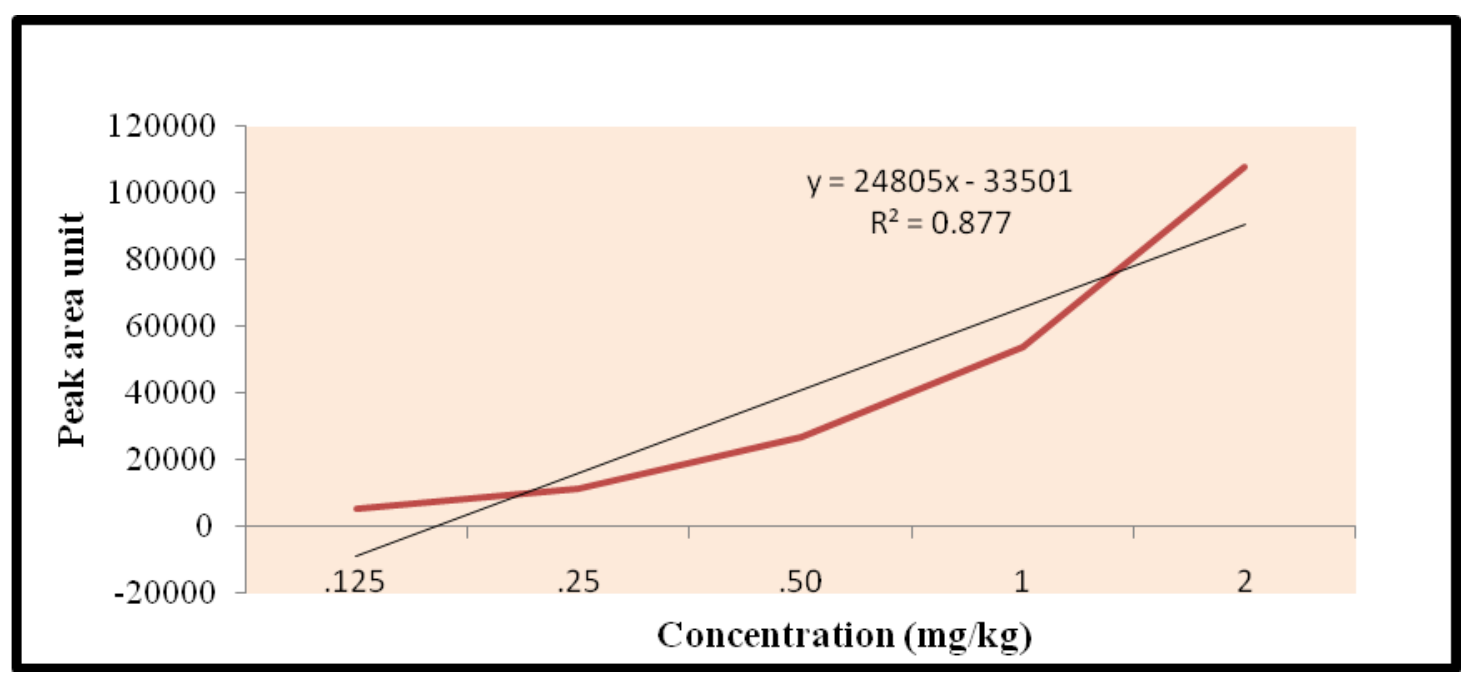

Fig.3 Calibration curve for lambda-cyhalothrin 
$\mathrm{mV}$

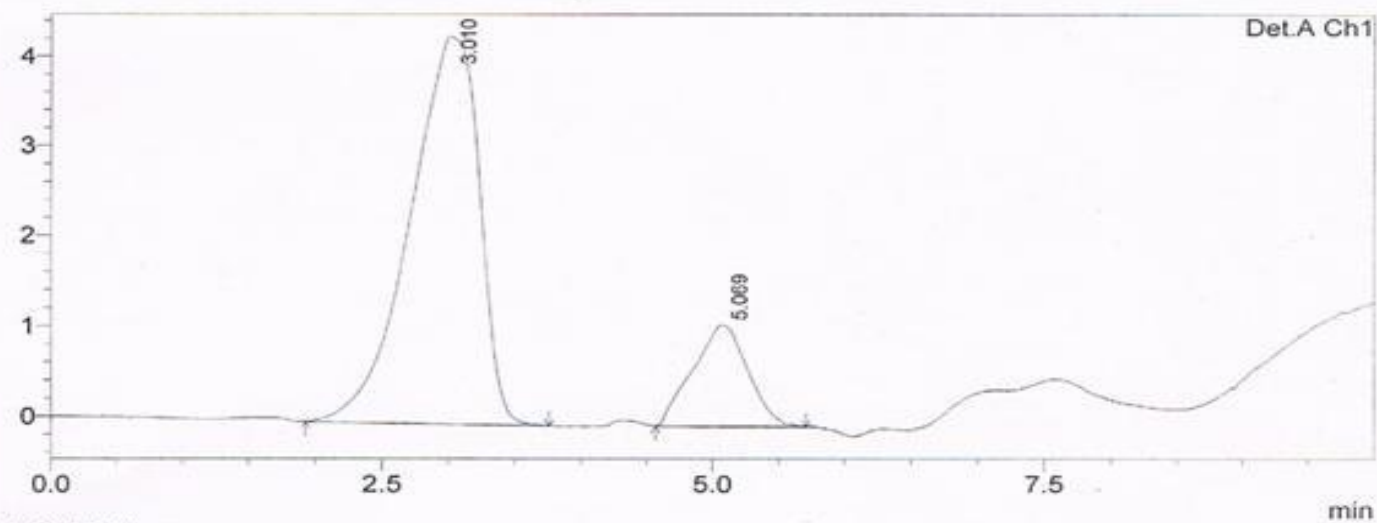

1 Det.A Ch1/270nm

\section{Chromatogram of imidacloprid}

$\mathrm{mV}$

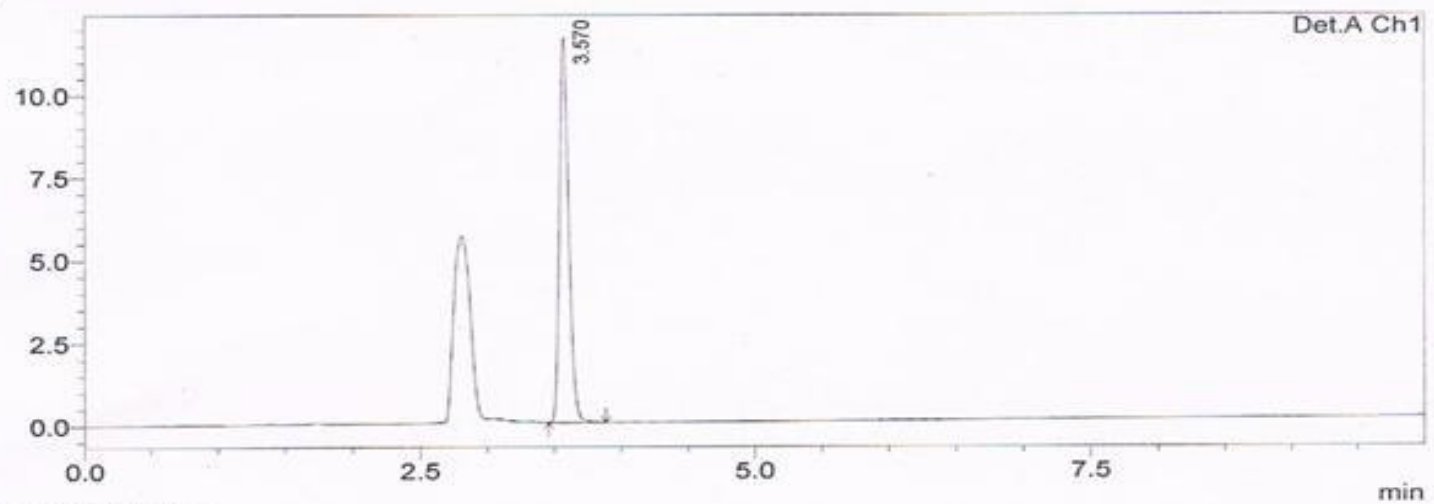

1 Det.ACh $1 / 310 \mathrm{~nm}$

Chromatogram of indoxacarb

$\mathrm{mV}$

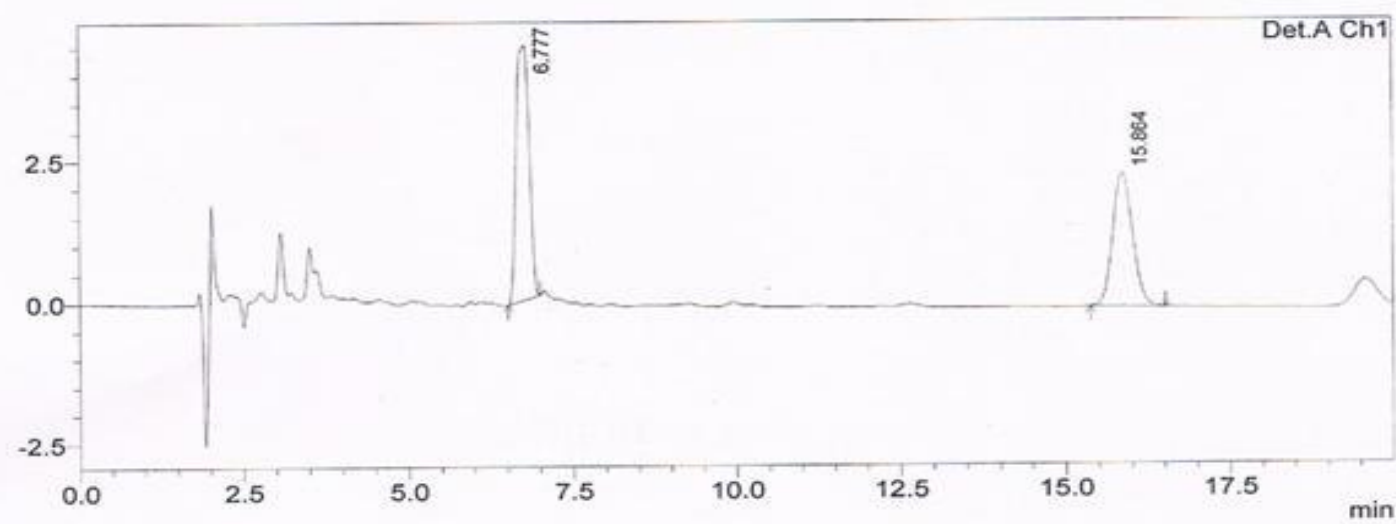

1 Det.A Ch1/230nm

\section{Chromatogram of lambda-cyhalothrin}

Fig.4 Chromatogram of standard insecticides by HPLC 


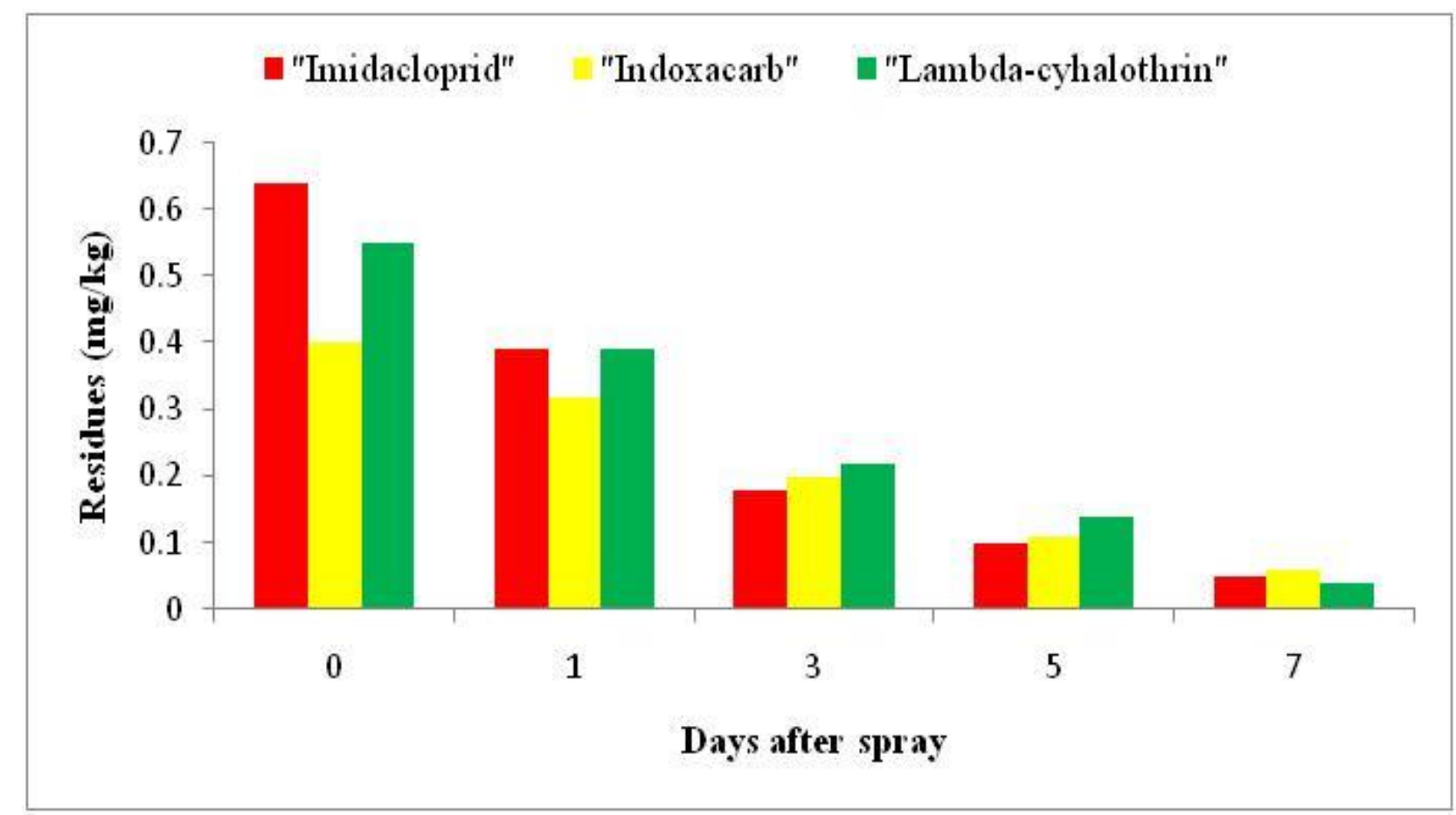

Fig.5 Residues of imidacloprid and indoxacarb in tomato fruits during winter season, 2015 and lambda-cyhalothrin in summer, 2016 


\section{Safety intervals}

A waiting period of 0.36 days was required for imidacloprid $(0.018 \%)$ sprayed on tomato crop. The waiting periods for lambdacyhalothrin and indoxacarb were worked out to be 1.03 and 0.46 days, respectively. The present findings are contrary to the results of Suganthy et al., (2010) who worked out a safe waiting period of 1.2-4.5 days for imidacloprid on chilli fruits. A waiting period of 3 days was suggested for imidacloprid on tomato (Dharmurajan and Dikshit, 2010). A waiting period of 3 days for indoxacarb on brinjal fruits was suggested (Saimandir and Gopal, 2009). Safety interval of 3 days for lambda-cyhalothrin on tomato was also reported (Reddy et al., 2007b). This might be due to different agro-ecological regions and type of spray equipments used in the present studies as well as time of sampling and analysis.

The results showed that the initial residues of imidacloprid and indoxacarb at their recommended concentrations were below their tolerance limits, however, the initial deposits of lambda-cyhalothrin were above the tolerance limit. Therefore, to be on safer side, a waiting period of at least 1 day should be observed for consumption of tomato fruits sprayed with imidacloprid, indoxacarb and lambda-cyhalothrin.

\section{References}

Ahmed, M.A.H., Baha Eldein, H.Y., Abd Elaziz, S.A.I., Azhari, O.A., Mark, D.L. 2015. Detection of insecticide residues on tomato fruits grown in greenhouses in Khartoum state. University of Khartoum Journal of Agricultural Science, 23, 49-65.

Anonymous, 2012. Retrieved online, http://www.cafeextention.org.in/CAFT201 2 Lecture, 18.pdf

Anonymous, 2014. Economic Survey 20132014. Economics and Statistics
Department, Government of Himachal Pradesh p 50.

Chauhan, R., Monga, Samriti and Kumari, B. 2011. Effect of processing on the reduction of $\lambda$-cyhalothrin residues in tomato fruits. Bulletin of Environmental Contamination and Toxicology, 88, 352-357.

Dharmurajan, S. and Dikshit, A.K. 2010. Effect of household processing on reduction of combination-mix $\quad(\beta$-cyfluthrin + imidacloprid) residues on tomato (Lycopersicon esculentum Mill). Pesticide Research Journal, 22, 32-34.

Faqiri, M. and Kumar, A. 2016. Management of tomato fruit borer (Helicoverpa armigera (Hubner) by chemical insecticides and neem products. International Journal of Multidisciplinary Research and Development, 3, 82-85.

Farouk, M., Hussain, L.A.A. and Azab, N.F. 2014. Different techniques for determination of imidacloprid insecticide residues. International Journal of Environment and Analytical Chemistry, 94, 194-209.

Gupta, S., Sharma, R.K., Gupta, R.K., Sinha, S.R., Singh, R. and Gajbhiye, V.T. 2009. Persistence of new insecticides and their efficacy against insect pest of okra. Bulletin of Environmental Contamination and Toxicology, 82, 243-247.

Gupta, S.P., Singh, S.P., Satyanarayana, Paidi and Kumar, Nagendra. 2015. Dissipation and decontamination of imidacloprid and lambda-cyhalothrin residues in brinjal. International Journal of Plant Protection, 8, 379-383.

Hoskins, W.M. 1961. Mathematical treatment of the rate of loss of pesticide residues. Plant Protection Bulletin, FAO, 9, 163168.

Jayakrishnan, S., Dikshit, A.K., Singh, S.P. and Pachauri, D.C. 2005. Dissipation of lambda-cyhalothrin on tomato (Lycopersicon esculentum Mill.) and removal of its residues by different washing process and steaming. Bulletin of Environmental Contamination and Toxicology, 75, 324-328. 
Kakar, K.L., Bhalla, O.P. and Dhaliwal, H.S. 1990. Screening of tomato germplasm and breeding for resistance against fruit borer (Helicoverpa armigera). Indian Journal of Insect Science, 3, 57.

Mustafiz, S.S.B., Chowdhury, M.T.I. and Akter, A. 2015. Efficacy of some botanicals in controlling fruit borer (Heliothis armigera) in tomato. Academic Journal of Entomology, 8, 140-149

Nasr, H.M., Abassy, M.A., Marzouk, M.A. and Mansy, A.S. 2014. Determination of imidacloprid and tetraconazol residues in cucumber fruits. Journal of Pollution Effects and Control, 2, 1-5.

Pareek, P.L. and Bhargava, M.C. 2003. Estimation of avoidable losses in vegetables caused by borers under semi arid condition of Rajasthan. Insect Environment, 9, 59-60.

Reddy, K.N., Satyanarayana and Reddy, K.D. 2007b. Persistence of some insecticides in chillies. Pesticide Research Journal, 19, 234-236.

Reddy, S.G.E., Sharma, D. and Kumar, N.K.K. 2007a. Residues of insecticides on sweet pepper and tomato grown under greenhouse and open field cultivation. Pesticide Research Journal, 19, 239-243.

Saimandir, J. and Gopal, M. 2009. Application of indoxacarb for managing shoot and fruit borer of egg plant (Solanum melongena L.) and its decontamination. Journal of Environmental Science and Health, 44, 292-301.

Saryazdi, G.A., Hejazi, M.J. and Saber, M. 2012. Residual toxicity of abamectin, chlorpyriphos, cyromazine, indoxacarb and spinosad on Liriomyza trifoli (Burgess) (Diptera: Agromyzidae) in greenhouse conditions. Pesti Phytomedicine (Belgrade), 27, 107-116.

Sharma, D. and Mohapatra, S. 2005. Dissipation pattern of indoxacarb and thiamethoxam residues in vegetables. Journal of Vegetable Science, 32, 166-168.

Sharma, K.C., Chauhan, U., Verma, A.K. 2004. Insect pests of vegetable crops: Identification and Management Manual. Department of Entomology and Apiculture, Dr. Y. S. Parmar University of Horticulture and Forestry, Solan. 63 pp.

Singh, B. 2005. Protected Cultivation of Vegetable Crops. Kalyani Publishers, New Delhi, India. p 168.

Singh, B., Takkar, R., Kaur, S., Rani, S. and Battu, R.S. 2011b. Estimation of residues of spirotetramat and imidacloprid in okra fruits. In: $3^{\text {rd }}$ Congress on Insect Science: Pest Management for Food Security and Environmental Health (Eds. AK Dhawan, DR Sharma and Rajinder Kumar) PAU Ludhiana p 228.

Suganthy, M., Kuttalam, S. and Chandrasekhar, S. 2010. Determination of waiting period and harvest time residues of imidacloprid 17.8SL in chillies. Madras Agriculture Journal, 97, 275.

Vashisth, S. 2009. Insect and nematode complex associated with some important polyhouse crops. M.Sc. Thesis, Department of Entomology, CSK Himachal Pradesh Krishi Vishvavidyalaya, Palampur, India. p 76.

Vladi, V., Harizaj, F., Vorpsi, V. and Cara, M. 2014. The degradation of the insecticide imidacloprid in greenhouse tomatoes and an estimation of the level of residues. Albanian Journal of Agricultural Sciences (Special Issue), 123-126.

\section{How to cite this article:}

Prem Chand Sharma, Priyanka, Chandresh and Sugandha Sharma. 2018. Persistence of Imidacloprid, Indoxacarb and Lambda-Cyhalothrin on Tomato (Solanum lycopersicum L.) Under Protected Cultivation. Int.J.Curr.Microbiol.App.Sci. 7(07): 2783-2794. doi: https://doi.org/10.20546/ijcmas.2018.707.325 